\title{
A female patient with retinoblastoma and severe intellectual disability carrying an X;13 balanced translocation without rearrangement in the $R B 1$ gene: a case report
}

\author{
Makiko Tsutsumi ${ }^{1}$, Hiroyoshi Hattori ${ }^{2,3}$, Nobuhiro Akita ${ }^{3}$, Naoko Maeda ${ }^{3}$, Toshinobu Kubota ${ }^{4}$, Keizo Horibe ${ }^{3}$, \\ Naoko Fujita ${ }^{1,5}$, Miki Kawai ${ }^{1}$, Yasuko Shinkai ${ }^{1}$, Maki Kato ${ }^{1}$, Takema Kato ${ }^{1}$, Rie Kawamura', Fumihiko Suzuki ${ }^{6}$ and \\ Hiroki Kurahashi ${ }^{1 *}$ (D)
}

\begin{abstract}
Background: Female carriers of a balanced $X$; autosome translocation generally undergo selective inactivation of the normal $X$ chromosome. This is because inactivation of critical genes within the autosomal region of the derivative translocation chromosome would compromise cellular function. We here report a female patient with bilateral retinoblastoma and a severe intellectual disability who carries a reciprocal X-autosomal translocation.

Case presentation: Cytogenetic and molecular analyses, a HUMARA (Human androgen receptor) assay, and methylation specific PCR (MSP) and bisulfite sequencing were performed using peripheral blood samples from the patient. The patient's karyotype was 46,X,t(X;13)(q28;q14.1) by G-banding analysis. Further cytogenetic analysis located the entire RB1 gene and its regulatory region on $\operatorname{der}(X)$ with no translocation disruption. The $X$-inactivation pattern in the peripheral blood was highly skewed but not completely selected. MSP and deep sequencing of bisulfite-treated DNA revealed that an extensive 13q region, including the $R B 1$ promoter, was unusually methylated in a subset of cells.
\end{abstract}

Conclusions: The $\operatorname{der}(X)$ region harboring the RB1 gene was inactivated in a subset of somatic cells, including the retinal cells, in the patient subject which acted as the first hit in the development of her retinoblastoma. In addition, the patient's intellectual disability may be attributable to the inactivation of the $\operatorname{der}(X)$, leading to a $13 q$ deletion syndrome-like phenotype, or to an active X-linked gene on der (13) leading to Xq28 functional disomy.

Keywords: Retinoblastoma, Balanced X-A translocation, X-inactivation

\section{Background}

Balanced translocations generally have no impact on the clinical phenotype of the carrier unless the breakpoint disrupts a dosage sensitive gene. However, $\mathrm{X}$; autosome (X-A) translocations in females are more complex because of the $\mathrm{X}$-chromosome inactivation $(\mathrm{XCI})$, which is a mechanism of dosage compensation of X-linked genes

\footnotetext{
* Correspondence: kura@fujita-hu.ac.jp

1Division of Molecular Genetics, Institute for Comprehensive Medical Science, Fujita Health University, 1-98 Dengakugakubo, Kutsukake-cho, Toyoake, Aichi 470-1192, Japan

Full list of author information is available at the end of the article
}

between females and males $[1,2]$. Since the derivative chromosome of an X-A translocation harboring the Xinactivation center may be subject to inactivation, its autosomal region is subject to unfavorable inactivation. This results in cellular dysfunction due to inactivation of critical genes leading to the pathological change or death of cells. In consequence, cells in females carrying an XA translocation generally undergo selective inactivation of the normal $\mathrm{X}$ chromosome.

Retinoblastoma (RB, OMIM \#180200) is a malignant intraocular tumor occurring in young children, which is caused by mutations in both alleles of the RB1 gene [3]. 
Individuals with heterozygous germline pathogenic variations frequently develop bilateral retinoblastoma in infancy. Constitutional chromosomal abnormalities involving 13q14, where the $R B 1$ gene is located, are found in a subset of cases with a predisposition for $\mathrm{RB}$. Large deletions that include the $R B 1$ gene lead to widely variable clinical phenotypes, including intellectual disability, referred to as $13 \mathrm{q}$ deletion syndrome $[4,5]$. We here describe a female patient with bilateral retinoblastoma and severe intellectual disability who was found to carry an X;13 translocation. Cytogenetic and molecular analysis revealed inactivation of $\operatorname{der}(\mathrm{X})$ and the $R B 1$ gene in a subset of her cells, which explains the cause of her phenotype.

\section{Case presentation}

\section{Cytogenetic analysis}

Blood samples from the study subjects were obtained with informed consent in accordance with local institutional review board guidelines. An Epstein-Barr virus (EBV) transformed Lymphoblastoid cell line (LCL) was established from the peripheral blood derived from the patient as described previously [6]. Conventional G-banding and fluorescence in situ hybridization (FISH) analyses were performed using LCL. Cytogenetic analyses were performed using a standard method. The ZytoLight SPEC RB1/13q12 Dual Color Probe (ZytoVision GmbH, Bremerhaven, Germany) was used to detect the $R B 1$ gene. A bacterial artificial chromosome (BAC) DNA was labeled with SpectrumGreen or SpectrumOrange-labeled 2'deoxyuridine- 5 '-triphosphate using the Nick-Translation Kit (Abbott Japan, Tokyo, Japan). To visualize late replicating regions, LCL was arrested with thymidine $(300 \mu \mathrm{g} /$ $\mathrm{ml}$ ) for $18.5 \mathrm{~h}$ followed by a treatment with bromodeoxyuridine (BrdU; $25 \mu \mathrm{g} / \mathrm{ml}$ ) for $6.5 \mathrm{~h}$ after release from the arrest. Metaphase cells were labeled with a FISH probe for the $\mathrm{X}$ chromosome centromere (Cytocell, Cambridge, UK), and BrdU was detected with Alexa Fluor 594conjugated mouse anti-BrdU antibody (ThermoFisher Scientific, Tokyo, Japan).

\section{HUMARA assay}

For HUMARA assays, genomic DNA was extracted from peripheral blood or LCL using the QuickGene DNA whole blood DNA kit L (Kurabo, Osaka, Japan). Restriction enzyme treatment followed by PCR analysis was then conducted as described previously [7].

\section{Methylation-specific PCR}

Bisulfite conversion of genomic DNAs obtained from the peripheral bloods of the patient and healthy human volunteers was first performed with the Epitect Bisulfite kit (QIAGEN, Tokyo, Japan). PCR was then carried out using EpiTaq HS (Takara, Kusatsu, Japan). EpiScope Methylated HeLa gDNA (Takara) was used as a positive control. The primers used in these analyses were designed with the BiSearch software [8] and are listed in Table 1.

\section{Bisulfite sequencing}

The $R B 1$ promoter region was amplified by PCR as described previously [9]. The PCR products were then used as the template for secondary PCR with primers containing sequencing adaptors. Amplicon sequencing was subsequently performed on an Illumina MiSeq in accordance with the manufacturer's protocol to obtain paired-end 150 bp reads. Sequencing data were analyzed with Bismark software [10].

\section{Patient characteristics}

The current study patient was a Japanese girl born at full term with a length of $50 \mathrm{~cm}$ and birth weight of $2894 \mathrm{~g}$. G-banding analysis was performed because of her inadequate weight gain at 1 month of age and revealed a de novo balanced reciprocal translocation, $t(X ; 13)(q 28$; q14.1) (Fig. 1a). She achieved head control at 6 months of age, began to sit up at 10 months, to pull up to a standing position at 12 months, and to walk at 30 months. At 18 months of age, her body length was 74.3 $\mathrm{cm}(-1.9 \mathrm{SD})$, and her weight was $8.3 \mathrm{~kg}(-1.6 \mathrm{SD})$. She was diagnosed with a unilateral retinoblastoma in the left eye (International Intraocular Retinoblastoma Classification, Group D) at 18 months of age. She was then treated with 4 cycles of systemic chemotherapy (vincristine, etoposide, and carboplatin). She suffered from chemotherapy-induced constipation during that period.

The parents refused consent for enucleation of the patient's left eye although her response to the chemotherapy was found to be inadequate, and side effects such as a tubular disorder were observed. We thus planned for an intra-arterial chemotherapy regimen due to the parents' wishes. New lesions were developed in the right eye four months later however while waiting for the intra-arterial chemotherapy. Three cycles of intra-arterial chemotherapy for the left eye and various cycles of laser transpupillary thermotherapy (4 cycles for left eye and 2 cycles for right eye) managed to control both eyes and maintain remission for 18 months. However, the retinoblastoma eventually relapsed in the left eye and this was followed by enucleation. The patient was still not talking at 6 years of age, and was thus manifesting severe speech, language and developmental disorders.

\section{Breakpoint analysis of chromosome 13}

To examine the underlying causes of the phenotype that manifested in our study patient, we analyzed the $R B 1$ gene by FISH because the chromosome 13 breakpoint was found to be located close to this gene locus at the 
Table 1 Primers used for MSP in this study

\begin{tabular}{|c|c|c|c|}
\hline Primer $^{a}$ & Forward (5'-3') & Reverse (5'-3') & Size $(b p)$ \\
\hline RB1-M & GGGAGTTTCGCGGACGTGAC & ACGTCGAAACACGCCCCG & 163 \\
\hline $\mathrm{RB} 1-\mathrm{U}$ & GGGAGTITTGTGGATGTGAT & ACATCAAAACACACCCCA & 163 \\
\hline q13.1-M & AAAACCCGAACGCAACGAAC & TCGTCGTAGTTGTTATCGTC & 120 \\
\hline q13.1-U & AAAACCCAAACACAACAAAC & TTGTTGTAGTTGTTATTGTT & 120 \\
\hline q14.11-M & GCGCGATGGAGTITIAGTAC & CGAAAAAAAACCCGAACGAC & 214 \\
\hline q14.11-U & GTGTGATGGAGTTTAAGTAT & CAAAAAAAAACCCAAACAAC & 214 \\
\hline q14.3-M & CCGCCTAACGTCAATAAAAC & GTGTTTAGAACGACGGGTGC & 160 \\
\hline q14.3-U & CCACCTAACATCAATAAAAC & GTGTTTAGAATGATGGGTGT & 160 \\
\hline q21.33-M & TAGGTTCGTITTCGCGTTC & CTTTAACTCCCCGCTTCCGC & 226 \\
\hline q21.33-U & TAGGTTTGTTITTGTGTT & CTTTAACTCCCCACTTCCAC & 226 \\
\hline q31.1 prox-M & AGATTCGGCGTTAGGTAGGGC & CGCGCTCTAAAAAATTAAAAC & 368 \\
\hline q31.1 prox-U & AGATTTGGTGTTAGGTAGGGT & CACACTCTAAAAAATTAAAAC & 368 \\
\hline q31.1 dis-M & CGTACTACTACCCCCGCTAC & GCGTIITTAGCGTITITA & 194 \\
\hline q31.1 dis-U & CATACTACTACCCCCACTAC & GTGTTITTAGTGTIIITAA & 194 \\
\hline q31.2-M & GCCGCTACGCTAAAAAACGA & CGTATITTCGGTITGGGTTCGC & 283 \\
\hline q31.2-U & ACCACTACACTAAAAAACAA & TGTATTTITGGTTTGGGTTGT & 283 \\
\hline q31.3-M & ACGAAATACCTACGCGCCAAC & CGCGGGTTAATAAAGTTIAC & 149 \\
\hline q31.3-U & ACAAAATACCTACACACCAAC & TGTGGGTTAATAAAGTTTAT & 149 \\
\hline q32.3-M & CGCGACTCCGAACAATAACC & AATGTAGTTATAATCGCGGC & 243 \\
\hline q32.3-U & CACAACTCCAAACAATAACC & AATGTAGTTATAATTGTGGT & 243 \\
\hline q34-M & AGGTTATAGGTTAGACGCGGC & CGAAACGAACGAAAACTAAC & 252 \\
\hline q34-U & AGGTTATAGGTTAGATGTGGT & CAAAACAAACAAAAACTAAC & 252 \\
\hline
\end{tabular}

a Given as the corresponding chromosomal band of the long arm of chromosome 13

G-banding level (Fig. 1a). RB1 signals were detected on the normal chromosome 13 and on $\operatorname{der}(\mathrm{X})$, indicating no breakpoint in the $R B 1$ gene (Fig. 1b). Further FISH analysis with BAC clones mapped the breakpoint to between RP11-179A7 (13q13.2) and RP11-91 K18 (13q13.3), which was 12 to $15 \mathrm{Mb}$ upstream of the $R B 1$ locus (Fig. 1c). These results indicated that the translocation in our patient did not disrupt the $R B 1$ gene or its regulatory region. Whole genomic microarray analysis and sequencing of the coding regions of the $R B 1$ gene revealed no copy number changes or nucleotide variations (data not shown). Thus, we could not map the precise location of the translocation breakpoint using microarray.

\section{XCl patterns}

We next assessed whether the $\operatorname{der}(\mathrm{X})$ region had been subjected to $\mathrm{XCI}$, which could inactivate $R B 1$ and nearby genes leading to the retinoblastoma and other symptoms observed in the patient. A HUMARA assay was performed using genomic DNA extracted from peripheral blood. The XCI of allele- 1 and -2 was 90.2 and $9.8 \%$, respectively (Fig. 2a). To determine which alleles of the androgen receptor gene were located on $\operatorname{der}(\mathrm{X})$, we carried out BrdU labeling of the late-replicating heterochromatin in an EBV-transformed LCL (Fig. 2b). Thirtyeight percent of the cells were BrdU-positive at the normal $X$, whereas the $\operatorname{der}(\mathrm{X})$ was positive in $62 \%$ of the cells. The XCI of allele- 1 and -2 was 29.3 and $70.7 \%$, respectively, in a HUMARA assay of the LCL (Fig. 2a). From these results, we considered allele- 1 to be linked to the normal $\mathrm{X}$ chromosome, indicating that the XCI was skewed to the normal $\mathrm{X}$ in the peripheral blood of our patient.

\section{Methylation of the RB1 gene and other regions of $13 q$}

To examine whether the $R B 1$ gene itself was inactivated in our patient, MSP was performed for the RB1 promoter using bisulfite-treated DNA as the template. PCR products were detected in the patient and in a positive control but not in a healthy control when a primer pair for amplifying methylated DNA was used (Fig. 3a). The methylation level of the $27 \mathrm{CpG}$ sites in the $R B 1$ promoter was then investigated using a deep sequencing approach [11]. The patient had a higher methylation frequency than a healthy control (Fig. 3b), with the highest frequency found to be $5.6 \%$ at position \#17 in her peripheral blood. Given our findings with the HUMARA 
A
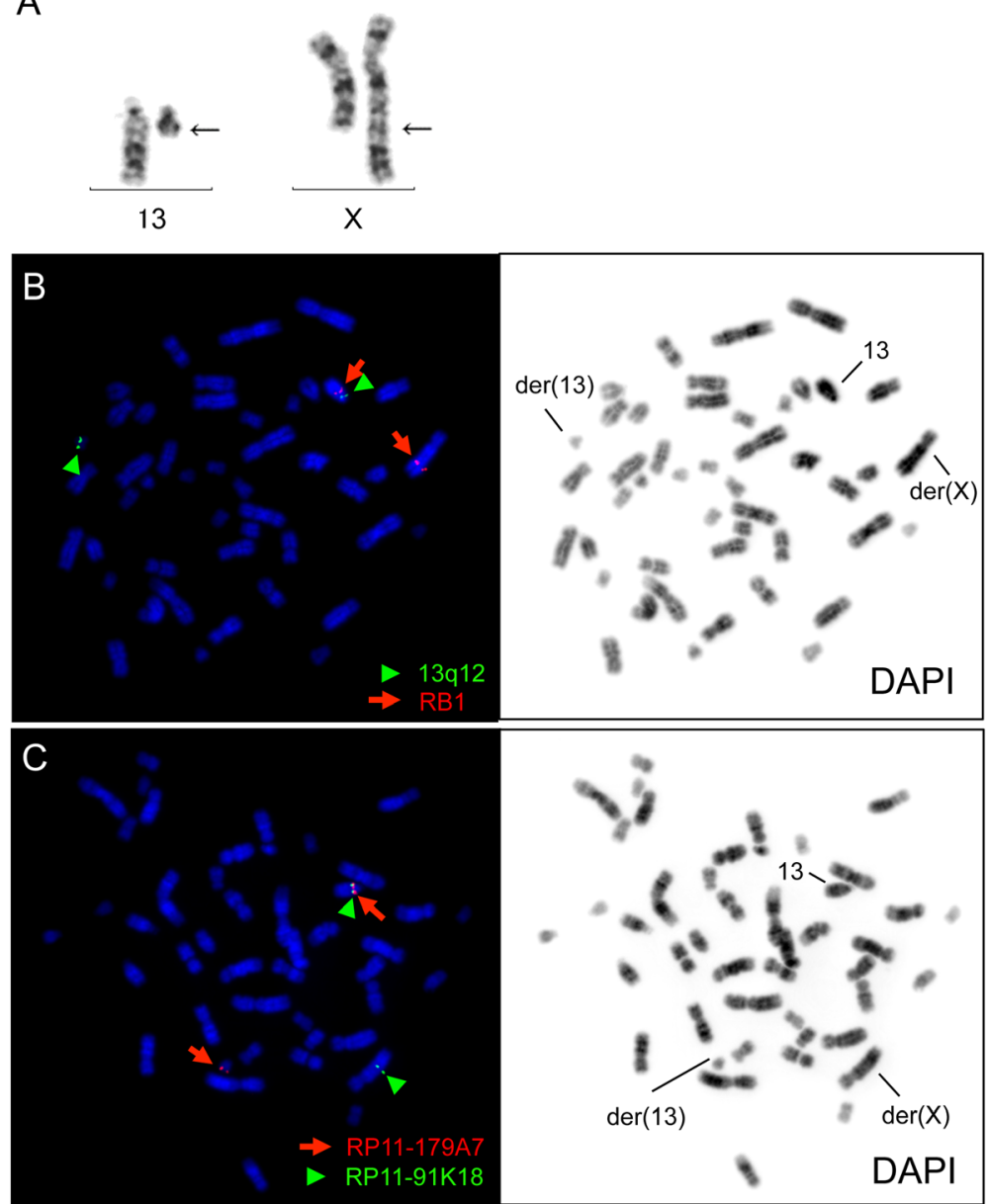

Fig. 1 G-banding and FISH analyses of the study patient. (a) A G-banded partial karyotype. The arrows indicate the breakpoints of the derivative chromosomes. (b) FISH analysis of the RB1 gene. The arrows and arrowheads indicate RB1 and 13q12 probes, respectively. (c) FISH analysis of the breakpoint on chromosome 13. The arrows and arrowheads indicate RP11-179A7 and RP11-91 K18 probes, respectively

assay in which $\sim 10 \%$ of the cells showed the $\operatorname{der}(\mathrm{X})$ inactivation (Fig. 2a), we speculated that one $R B 1$ allele in each cell might be inactivated. Since position \#17 is the activating transcription factor (ATF) binding site, methylation of this site might inhibit the binding of transcription factors [12].

We next demarcated the 13q region of inactivation on the $\operatorname{der}(\mathrm{X})$ using MSP (Table 2). The region proximal to the breakpoint was not found to be methylated, whereas those distal to it were extensively methylated in our study patient. Although methylation was also detected in regions distal to the $R B 1$ gene, those of $13 \mathrm{q} 31$ were not specific to the patient. Regions near to the 13q terminal were not methylated in the patient.

\section{Discussion and conclusions}

In a similar manner to our present patient, several prior cases of retinoblastoma carrying a constitutional X;13 translocation without disruption of the $R B 1$ gene had been reported [13-17] and described an inactivation of the derivative chromosome harboring the $R B 1$ gene [1823]. The breakpoints of most of these cases including our patient were located at 13q12-q14 regions. To our knowledge, our present case report is the first to demonstrate inactivation of the $R B 1$ gene at the molecular level i.e. by epigenetic mechanisms. Selective XCI in females with balanced X-A translocations is attributed to a haploinsufficiency of dosage sensitive genes near to the breakpoint in the autosomal region affecting cell viability. Our current case and similar prior retinoblastoma cases harboring $\mathrm{X} ; 13$ translocations suggest that there are no such critical genes near to the breakpoint on 13q. This would mean that selective XCI of the normal X chromosome in X-A translocation carriers is dependent on the translocation partner chromosome. Moreover, such dosage-sensitive genes may be different between cell lineages, leading to different levels of inactivation among tissues. The HUMARA analysis of the peripheral 


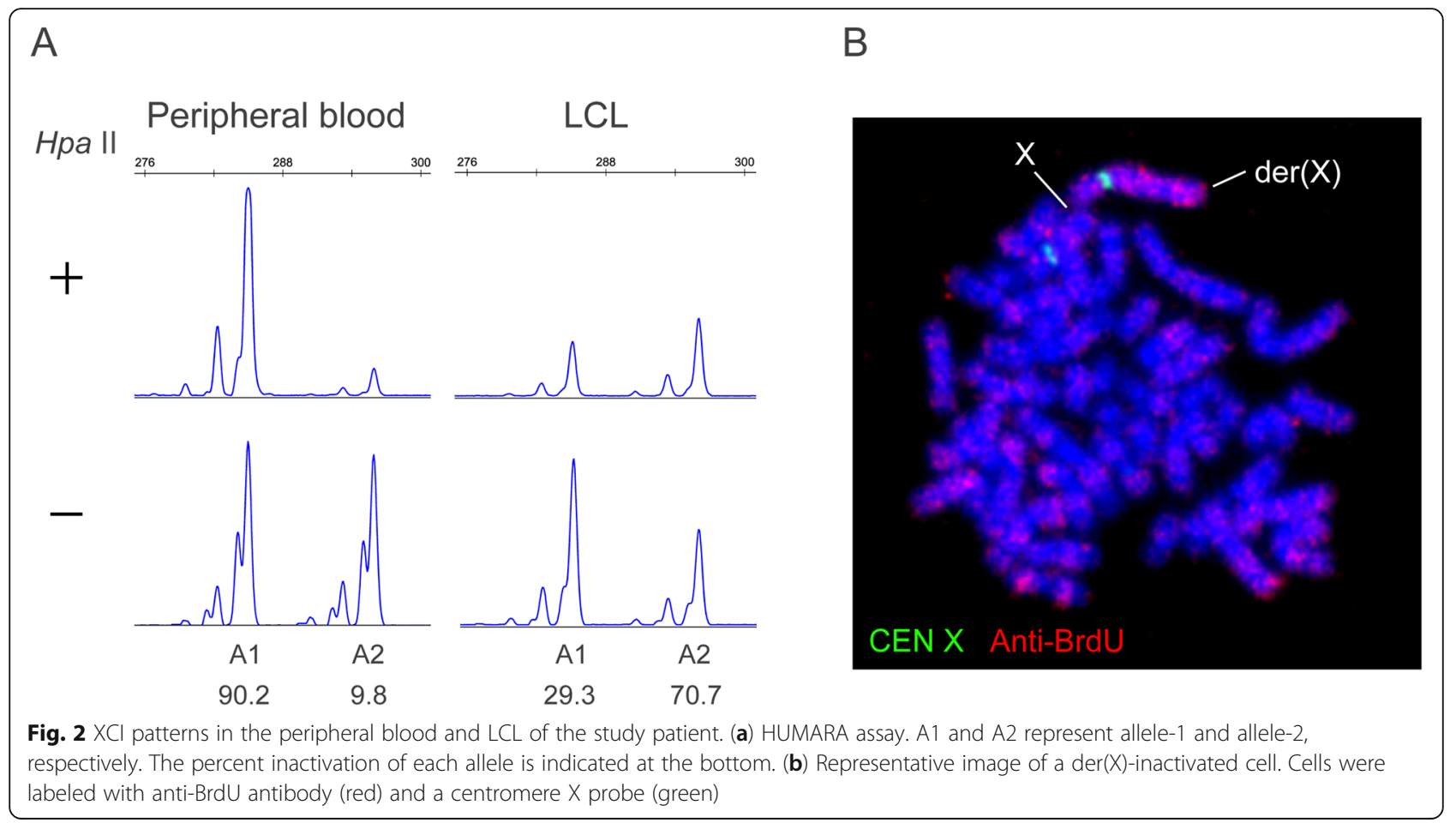

A

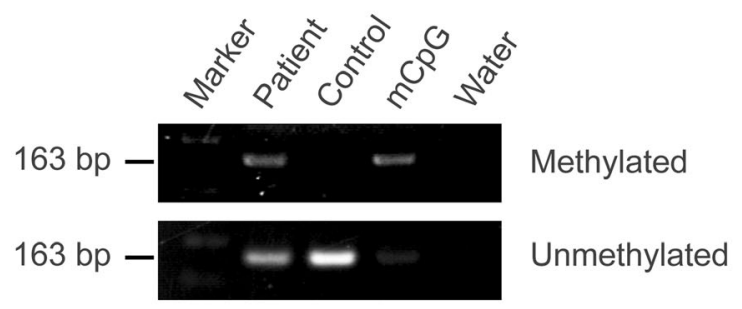

B

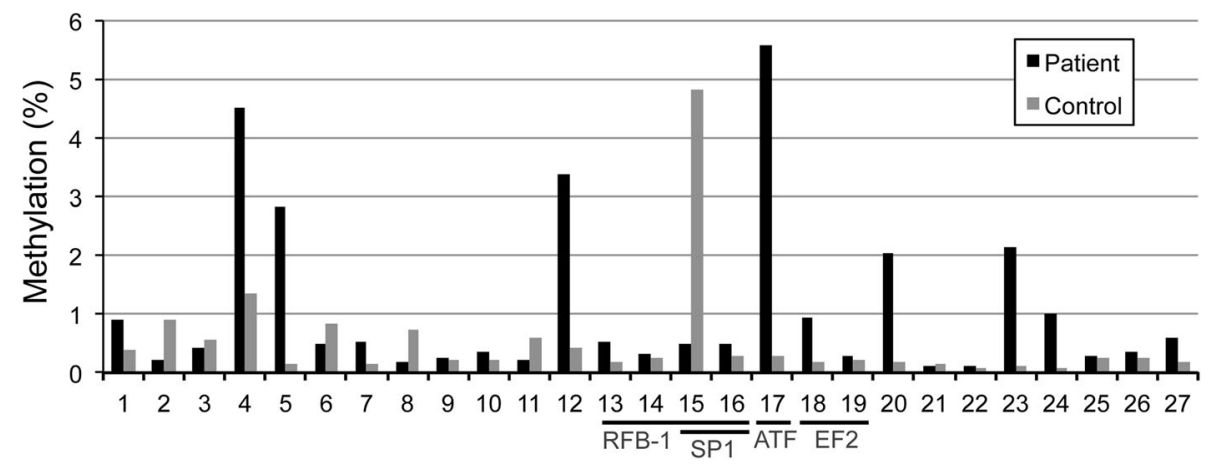

Fig. 3 Methylation analysis of the RB1 promoter in the study patient using bisulfite-treated DNA derived from peripheral blood. (a) Agarose gel electrophoresis of MSP products. Amplified products of methylated and unmethylated DNA are indicated. CpG methylated HeLa genomic DNA was used as a positive control (mCpG). (b) Frequency of methylation in the $27 \mathrm{CpG}$ sites obtained by bisulfite sequencing; $3.0 \times 10^{4}$ and $1.2 \times 10^{4}$ of next-generation sequencing reads were mapped to each CpG in the patient and healthy control, respectively. The CpGs located within transcription factor binding sites are underlined. Position \#15 is a common methylation site 
Table 2 MSP amplification of the $13 q$ region in the study patient and healthy controls

\begin{tabular}{|c|c|c|c|c|c|c|c|c|c|c|c|}
\hline & q13.1 & $q 14.11$ & q14.2 (RB1) & q14.3 & $\mathrm{q} 21.33$ & q31.1 prox & q31.1 dis & q31.2 & q31.3 & q32.3 & q34 \\
\hline Patient & - & + & + & + & + & + & + & + & + & - & - \\
\hline Control-1 & - & - & - & - & - & +- & + & +- & + & - & - \\
\hline Control-2 & n.d. & n.d. & n.d. & n.d. & - & + & + & n.d. & - & +- & n.d. \\
\hline Control-3 & n.d & n.d. & n.d & n.d. & - & - & + & n.d. & +- & - & n.d. \\
\hline
\end{tabular}

n.d.: not determined

blood from our current study patient revealed that the normal X was inactivated in $90 \%$ of the cells. Although specimens from other tissues in our subject were not available, we speculated that a high frequency of $\operatorname{der}(\mathrm{X})$ inactivation would be likely in the retinal cell lineage since our patient suffered from bilateral retinoblastoma. The retinal cell lineage has a relative tolerance to the inactivation of $13 \mathrm{q}$ and ironically develop RB. Furthermore, the systemic phenotype of our current study patient other than retinoblastoma implied the presence of a considerable number of cells with an inactivated $\operatorname{der}(\mathrm{X})$.

The $13 \mathrm{q}$ deletion syndrome is classified into three types depending on the deleted region [5, 24]. Group 1 comprises patients with deletions proximal to $13 \mathrm{q} 32$ who show mild or moderate intellectual disability, minor malformations, constipation, growth retardation and inconstant retinoblastoma. Group 2 comprises cases of deletions encompassing 13q32 that show severe intellectual disability, growth retardation, one or more major malformations of the brain, genitourinary and gastrointestinal tract, and distal limb. Group 3 comprises patients with deletions distal to $13 \mathrm{q} 32$ who show severe intellectual disability without major malformations or growth retardation. The inactivated region of $13 q$ in our current patient corresponded to group 1 (Table 2), and she had both growth retardation and constipation. However, her intellectual phenotype was more severe than was typically seen in patients categorized as group 1 .

We speculated that the cause of the severe phenotype in our patient originated from a functional disomy of Xq28 which was translocated to der (13). Functional disomy is a situation in which X-linked genes, normally expressed monoallelically, are expressed biallelically in
A

Standard X-A translocation

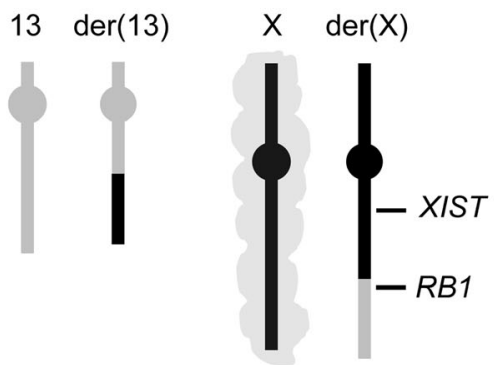

The normal $X$ is inactivated in $100 \%$ of cells

No symptoms
B

\section{Case $t(X ; 13)(q 28 ; q 14.1)$}

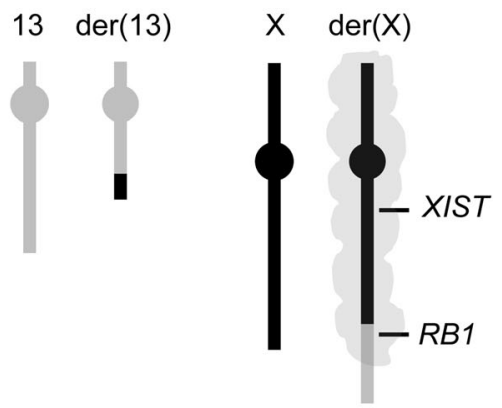

The $\operatorname{der}(\mathrm{X})$ is inactivated in a subset of the cells

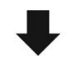

Retinoblastoma

$13 q$ deletion syndrome

Xq28 functional disomy

Fig. 4 Schematic representation of the XCl pattern and its outcomes with X-A translocation. (a) In a standard X-A translocation, the normal X chromosome is inactivated in 100\% of the cells because inactivation of the $\operatorname{der}(X)$ often leads to suppression of genes indispensable for cell survival. In this situation, the gene dosage is normal and the carrier has no symptoms. (b) In the present study case, the der $(X)$ was inactivated in a subset of the cells in which $13 q$ genes including $R B 1$ on the $\operatorname{der}(X)$ were suppressed. This inactivation does not spread to the $13 q$ terminal because of its long distance from the X-inactivation center, allowing the cells to survive. In der(13), the genes located at Xq28 are active. This results in retinoblastoma, 13q deletion syndrome- and an Xq28 functional disomy-like phenotype in such cells 
individuals carrying chromosome $\mathrm{X}$-involved structural variants with an unfavorable XCI pattern. As a result, Xlinked genes are expressed at a 2 -fold higher level than normal [25]. In this case, the $\operatorname{der}(\mathrm{X})$ was possibly inactivated in the brain of the patient derived from the common ancestral cell lineage with retina. Thus, Xq28 on the der (13) without the X-inactivation center likely escaped XCI resulting in a functional disomy. Severe developmental delays are common in patients with an Xq28 functional disomy, as was the case in our current patient [26]. The mechanism underlying the onset of retinoblastoma and 13q deletion syndrome- or an Xq28 functional disomy-like phenotype is illustrated in Fig. 4. Our patient was susceptible to the development of retinoblastoma because of the inactivation of the $R B 1$ gene on the $\operatorname{der}(\mathrm{X})$ in her retinal cell linage. A somatic mutation in the other allele on the normal chromosome 13 became the second hit.

We describe a female patient with retinoblastoma and severe intellectual disability, carrying an X;13 translocation. Her $R B 1$ gene was not disrupted by this translocation but became inactivated by the XCI system. Our current data have important clinical implications. Females carrying an $\mathrm{X} ; 13$ translocation should be followed-up closely for the early detection of retinoblastoma in infancy and other cancers throughout her life. This should be done even if the XCI is found to be $100 \%$ skewed in analysis of peripheral blood samples, because $\mathrm{XCI}$ patterns can vary in different tissues. Hence, a female retinoblastoma patient who is a suspected carrier of a germline mutation should be assessed using cytogenetic methods such as G-banding even when conventional analysis reveals no mutations of the $R B 1$ gene.

\section{Abbreviations \\ ATF: Activating transcription factor; BAC: Bacterial artificial chromosome; BrdU: Bromodeoxyuridine; EBV: Epstein-Barr virus; FISH: Fluorescence in situ hybridization; HUMARA: Human androgen receptor assay; \\ LCL: Lymphoblastoid cell line; MSP: Methylation specific PCR; \\ RB: Retinoblastoma; X-A: X;autosome; XCl: X-chromosome inactivation}

\section{Acknowledgements}

We thank to Narumi Kamiya for technical assistance.

\section{Authors' contribution}

MT, NF, RK and FS carried out the cytogenetic analysis; MT, MK, YS, MK and TK carried out molecular analysis; $\mathrm{HH}$ carried out the genetic counseling; $\mathrm{HH}$, NA, NM, TK and KH carried out the clinical management of the patient; MT, $\mathrm{HH}$ and $\mathrm{HK}$ designed the study and drafted the manuscript. All authors read and approved the final manuscript.

\section{Funding}

This study was supported by grants-in-aid for Scientific Research from the Ministry of Education, Culture, Sports, Science, and Technology of Japan, that from Ministry of Health, Welfare and Labor, and that from Japan Agency for Medical Research and Development.

\section{Availability of data and materials}

The datasets used and/or analysed during the current study are available from the corresponding author on reasonable request.

\section{Ethics approval and consent to participate}

The genetic testing used in this study was approved by the ethics committee of Fujita Health University in accordance with the principles of the Declaration of Helsinki, and the Ethical Guidelines for Human Genome/ Gene Analysis Research by the Ministry of Education, Culture, Science, and Technology, the Ministry of Health, Labor, and Welfare, and the Ministry of Economy, Trade, and Industry of Japan. Written informed consent was obtained from all of the participants or their parents in accordance with local institutional review board guidelines.

\section{Consent for publication}

Written informed consent was obtained from a parent of the patient for publication of this study.

\section{Competing interests}

The authors declare that they have no competing interests.

\section{Author details}

'Division of Molecular Genetics, Institute for Comprehensive Medical Science, Fujita Health University, 1-98 Dengakugakubo, Kutsukake-cho, Toyoake, Aichi 470-1192, Japan. ${ }^{2}$ Department of Clinical Genetics, National Hospital Organization, Nagoya Medical Center, Nagoya, Japan. ${ }^{3}$ Department of Pediatrics, National Hospital Organization, Nagoya Medical Center, Nagoya, Japan. ${ }^{4}$ Department of Ophthalmology, National Hospital Organization, Nagoya Medical Center, Nagoya, Japan. ${ }^{5}$ Genome and Transcriptome Analysis Center, Fujita Health University, Toyoake, Japan. ${ }^{6}$ Center for Collaboration in Research and Education, Fujita Health University, Toyoake, Japan.

Received: 27 September 2019 Accepted: 29 November 2019

Published online: 05 December 2019

\section{References}

1. Lyon MF. Some milestones in the history of X-chromosome inactivation. Annu Rev Genet. 1992;26:16-28.

2. Avner P, Heard E. X-chromosome inactivation: counting, choice and initiation. Nat Rev Genet. 2001;2(1):59-67.

3. Lohmann DR, Gallie BL. Retinoblastoma. In: Adam MP, Ardinger HH, Pagon RA, Wallace SE, bean LJH, Stephens K, Amemiya a, editors. GeneReviews ${ }^{\circledR}$ [internet]. Seattle (WA): University of Washington, Seattle; 1993-2019. https:// www.ncbi.nlm.nih.gov/books/NBK1452/. .

4. Allderdice PW, Davis JG, Miller OJ, Klinger HP, Warburton D, Miller DA, Allen FH Jr, Abrams CA, McGilvray E. The 13q-deletion syndrome. Am J Hum Genet. 1969;21(5):499-512

5. Mitter D, Ullmann R, Muradyan A, Klein-Hitpass L, Kanber D, Ounap K, Kaulisch M, Lohmann D. Genotype-phenotype correlations in patients with retinoblastoma and interstitial 13q deletions. Eur J Hum Genet. 2011;19(9): 947-58.

6. Tsutsumi M, Yokoi S, Miya F, Miyata M, Kato M, Okamoto N, Tsunoda T, Yamasaki M, Kanemura Y, Kosaki K, Saitoh S, Kurahashi H. Novel compound heterozygous variants in PLK4 identified in a patient with autosomal recessive microcephaly and chorioretinopathy. Eur J Hum Genet. 2016; 24(12):1702-6.

7. Kawai M, Tsutsumi M, Suzuki F, Sameshima K, Dowa Y, Kyoya T, Inagaki H, Kurahashi $\mathrm{H}$. Two siblings with 11qter deletion syndrome that had been rescued in their mother by uniparental disomy. Eur J Med Genet. 2019;62(3): 224-8.

8. Tusnády GE, Simon I, Váradi A, Arányi T. BiSearch: primer-design and search tool for PCR on bisulfite-treated genomes. Nucleic Acids Res. 2005;33(1):e9.

9. Quiñonez-Silva G, Dávalos-Salas M, Recillas-Targa F, Ostrosky-Wegman P, Aranda DA, Benítez-Bribiesca L. Monoallelic germline methylation and sequence variant in the promoter of the RB1 gene: a possible constitutive epimutation in hereditary retinoblastoma. Clin Epigenetics. 2016;8:1.

10. Krueger F, Andrews SR. Bismark: a flexible aligner and methylation caller for bisulfite-Seq applications. Bioinformatics. 2011;27(11):1571-2.

11. Stirzaker C, Millar DS, Paul CL, Warnecke PM, Harrison J, Vincent PC, Frommer M, Clark SJ. Extensive DNA Methylation spanning the Rb promoter in retinoblastoma tumors. Cancer Res. 1997;57(11):2229-37.

12. Ohtani-Fujita N, Fujita T, Aoike A, Osifchin NE, Robbins PD, Sakai T. CpG methylation inactivates the promoter activity of the human retinoblastoma tumor-suppressor gene. Oncogene. 1993;8(4):1063-7. 
13. Hida T, Kinoshita Y, Matsumoto R, Suzuki N, Tanaka H. Bilateral retinoblastoma with a 13qXp translocation. J Pediatr Ophthalmol Strabismus. 1980;17(3):144-6.

14. Ponzio G, Savin E, Cattaneo G, Ghiotti MP, Marra A, Zuffardi O, Danesino C. Translocation X;13 in a patient with retinoblastoma. J Med Genet. 1987; 24(7):431-4.

15. Stambolian D, Sellinger B, Derrington D, Sargent R, Emanuel BS. Cytogenetic and molecular investigation of a balanced Xq13q translocation in a patient with retinoblastoma. Am J Med Genet. 1992;42(6):771-6.

16. Laquis SJ, Rodriguez-Galindo C, Wilson MW, Fleming JC, Haik BG. Retinoblastoma in a patient with an $\mathrm{X} ; 13$ translocation and facial abnormalities consistent with 13q-syndrome. Am J Ophthalmol. 2002;133(2): 285-7.

17. Dries $D$, Baca $K$, Truss $L$, Dobin S. Interstitial deletion of $13 q$ and a 13;X chromosome translocation results in partial trisomy 13 and bilateral retinoblastoma. Ophthalmic Genet. 2003;24(3):175-80.

18. Cross HE, Hansen RC, Morrow G 3rd, Davis JR. Retinoblastoma in a patient with a 13qXp translocation. Am J Ophthalmol. 1977;84(4):548-54.

19. Nichols WW, Miller RC, Sobel M, Hoffman E, Sparkes RS, Mohandas T, Veomett I, Davis JR. Further observations on a 13qXp translocation associated with retinoblastoma. Am J Ophthalmol. 1980;89(5):621-7.

20. Ejima Y, Sasaki MS, Kaneko A, Tanooka H, Hara Y, Hida T, Kinoshita Y. Possible inactivation of part of chromosome 13 due to $13 \mathrm{qXp}$ translocation associated with retinoblastoma. Clin Genet. 1982;21(6):357-61.

21. Kajii T, Tsukahara M, Fukushima Y, Hata A, Matsuo K, Kuroki Y. Translocation $(X ; 13)(p 11.21 ; q 12.3)$ in a girl with incontinentia pigmenti and bilateral retinoblastoma. Ann Genet. 1985;28(4):219-23.

22. Gorski JL, Burright EN, Harnden CE, Stein CK, Glover TW, Reyner EL. Localization of DNA sequences to a region within Xp11.21 between incontinentia pigmenti (IP1) X-chromosomal translocation breakpoints. Am J Hum Genet. 1991;48(1):53-64.

23. Jones C, Booth C, Rita D, Jazmines L, Brandt B, Newlan A, Horsthemke B. Bilateral retinoblastoma in a male patient with an $X_{i} 13$ translocation: evidence for silencing of the RB1 gene by the spreading of $X$ inactivation. Am J Hum Genet. 1997:60(6):1558-62.

24. Brown S, Russo J, Chitayat D, Warburton D. The 13q- syndrome: the molecular definition of a critical deletion region in band 13q32. Am J Hum Genet. 1995;57(4):859-66.

25. Sanlaville D, Schluth-Bolard C, Turleau C. Distal Xq duplication and functional Xq disomy. Orphanet J Rare Dis. 2009;4:4.

26. Sanlaville D, Prieur M, de Blois MC, Genevieve D, Lapierre JM, Ozilou C, Picq M, Gosset P, Morichon-Delvallez N, Munnich A, Cormier-Daire V, Baujat G, Romana S, Vekemans M, Turleau C. Functional disomy of the Xq28 chromosome region. Eur J Hum Genet. 2005;13(5):579-85.

\section{Publisher's Note}

Springer Nature remains neutral with regard to jurisdictional claims in published maps and institutional affiliations.

Ready to submit your research? Choose BMC and benefit from:

- fast, convenient online submission

- thorough peer review by experienced researchers in your field

- rapid publication on acceptance

- support for research data, including large and complex data types

- gold Open Access which fosters wider collaboration and increased citations

- maximum visibility for your research: over $100 \mathrm{M}$ website views per year

At $\mathrm{BMC}$, research is always in progress.

Learn more biomedcentral.com/submissions 